Session 3592

\title{
Women Engineers: Preparing Them For The Workplace
}

\author{
Elaine Seat
}

\author{
University of Tennessee, Knoxville, Tennessee
}

\begin{abstract}
Introduction
The engineering workplace is changing, and one of the changes is in the gender mix of technical professionals. There are more women entering the engineering workforce, and with time, it is expected that women will compose a greater percentage of the total of engineers. However, simply because there are more women graduate engineers doesn't mean that they will remain in engineering for a career. A successful career depends on both technical competence and social skills, and a quality educational experience supplies both of these qualities. This paper examines the social side of a career in engineering for women and suggests techniques for improving social performance. It discusses reasons for attrition among women engineers, how women engineers view themselves, and how to coach women engineering students to have a more accurate self-perception to counter career dissatisfaction.
\end{abstract}

Retention of women is not only a problem in the technical disciplines, but is also a problem in many other professions. Anecdotal evidence suggests that women leave the science and engineering workforce and other professions such as law and finance by mid-career ${ }^{1,2}$. In women's athletics, it is disturbing to note that as the opportunities have increased for women to coach women's teams at all levels or to manage women's programs, the percentage of women in those jobs is decreasing ${ }^{3}$.

Several studies suggest that the real reason for poor retention among women in traditionally male professions is a result of incomplete occupational socialization. Incomplete occupational socialization is "when individuals or groups of individuals do not acquire the necessary knowledge, values, or skills to be socialized into an occupation adequately and are consequently not successful in and eventually drop out of the occupation"4. This concept suggests that women are socialized in a manner that doesn't fit the social patterns of the workplace with a resulting conflict of values and perceptions. The reward system of the workplace doesn't fit the value system of the individual, resulting in career dissatisfaction.

In the case of women engineers, they may not physically drop out of their profession, but they may become emotionally removed and unmotivated as they approach mid-career. The phenomenon of socialization differences is exhibited through the differences in interaction style and perceptions of aggression and ability. In a review of attitudes of and toward women engineers by Catalyst ${ }^{5}$, the example is given of how engineers gain respect through aggressive technical interchanges. This report found that when women behaved in this manner, they were thought to be overly aggressive and penalized, yet when they attempted to participate in a less aggressive style, they were not thought to be competent. With respect to technical competence and ability, women were thought less because they tended to not have "hands-on" tasks. The women reported feeling inadequate to do hands-on work, and often doubted their ability to 
perform in comparison to their male peers. But, engineering managers expressed concern about putting women in shop environments due to the dirty and crude nature of both the work and workers ${ }^{5}$. Women interpreted this reluctance as a reflection of their inability to do hands-on work and didn't realize that they were being protected by well-meaning supervisors.

In a review of other professions, Morris ${ }^{2}$ interviewed executive women who had left upper level management positions with large corporations. She found that these women left because they wanted to make a difference in their position of power, but felt that their men peers were only interested in the perks associated with power. This circumstance exemplifies incomplete occupational socialization because these women were socialized to feel rewarded by making a difference, not from perks and position. These women left their traditional jobs to move into roles that used their professional expertise, but had a focus of serving others.

Socialization differences between genders have an effect in the educational system through the perception of performance and ability. The norms and beliefs established in engineering school carry on into the workplace, and can have a devastating effect on careers. Engineering school is where one's self-perception of their engineering ability begins, and the self-confidence to be a problem solver is nurtured. For graduates to be productive engineers, the engineering education must teach not only the technical skills, but provide the self-confidence to creatively use these skills. Understanding perceptions of performance and replacing old beliefs with more realistic ones will better prepare individuals to interpret the workplace and perform at a high level.

Previous work in individual differences aids in understanding perceptions and beliefs. In achievement settings, gender differences have been reported with men having higher perceptions of internal competence than women. Women attribute success to ambiguous, unstable factors such as luck, while men attribute success to controllable factors such as skill or natural ability ${ }^{6}$. Women also tend to have lower expectations of success than men. Deaux suggests that women's self-confidence depends on three situational factors: 1) the nature of the task, 2) the nature of the feedback about performance, and the 3) nature of social comparisons. Application of these concepts both to the educational system and the workplace suggests that women's selfconfidence is increased as the task becomes more female-oriented, as feedback becomes more clear and performance can be evaluated unambiguously, and as the women performer's expectations or task performance match social attitudes about men and women.

In the context of engineering, a male-oriented profession, each of these situational factors provides fertile ground for women to have a negative perception. In a gender-inappropriate role as an engineer ${ }^{7}$, women are not expected to have the natural ability to perform traditionally male jobs. Cultural beliefs about the masculine nature of the engineering profession provide a general social perception that women can't perform the task comparably because they do not have innate ability. In the engineering workplace, the nature of engineering work lends itself to subjective, labeling terms. Certainly, engineering is task oriented, and achievement results from task performance. However, budget, schedule, or customer personal preference may influence the preferred solution more than technical correctness. Simply performing the task is not always enough and performance evaluation is often subjective. The educational system with its specific problem solving evaluating, is an ideal place to build a perception of ability through

demonstration of skills. Women expect to be less successful in achievement contexts ${ }^{8}$, and in 
evaluation of task performance, although an engineering solution may be correct, it may not be chosen for implementation for reasons that aren't clear in the workplace. The classroom provides a context for separating skill from subjective selection.

Self-perception is crucial to performance. Athletics clearly demonstrate that there is a direct correlation between self-confidence and success ${ }^{9}$. Self-talk that is misguided leads to confused, poor performance, while a realistic perspective leads to sound performance. Successful performers never downplay their abilities, instead, they speak confidently about their skills and visualize success. As Keith Bell ${ }^{10}$ states, it is not thinking itself that leads to poor performance, but inappropriate or misguided thinking.

Self-talk is often behind stress and inappropriate behaviors, and socialization provides us with many of our internal beliefs about who we are and our abilities. For women, the lack of socialization to support a technical career creates a scenario of improper perception and interpretation of performance and achievement. The self-talk of women engineers sets the stage for poor performance and dissatisfaction. Unfortunately, irrational thoughts never lead to improved performance, resulting in distorted perception which manifests in inappropriate behavior. Irrational thoughts predicate behaviors which cause others to respond irrationally toward the individual, creating a cycle of negative behaviors. As unexplainable behaviors happen, stress levels increase because of the unpredictable nature of the interaction.

Ellis categorized irrational beliefs and proposed methods to replace them with rational beliefs and coping skills ${ }^{11}$. Four types of irrational and distorted thinking that often plague women engineers in their evaluation of self are: 1) perfection reflects competence, 2) worth depends on achievements, 3) entitlement to fair treatment and ideal conditions, and 4) generalization from a single incident.

It is important to understand how women perceive themselves and their careers so that interventions can be used to enhance performance and offset attrition for that segment of the workforce. The picture of women in the technical workforce is not one of fulfilling careers, selfconfidence, and success. Changing their self-perception is crucial in enabling them to use their technical skills because one can only do what they perceive themselves to be capable of doing. Changing this perception begins in the educational system, and it unique for each gender.

\section{Perceptions of Women Engineers}

As a part of a large qualitative study into the perceptions and expectations of women engineers ${ }^{12}$, women engineers were asked What is your best quality? and How do you compare to your male peers? In this study, 21 women engineers ranging in ages from 25 to 40 and from a geographical cross section of the United States were interviewed in person about their expectations and perceptions of their engineering careers. These women all had a BS in an engineering discipline, and the majority of them either had completed or were working on technical Masters Degrees or MBAs.

A thematic analysis of the interviews resulted in identification of two themes:

1) Women engineers perceive hard work and perseverance as their best quality. 
2) Women engineers label themselves as average in ability, perceiving that their men counterparts are superior in ability, primarily due to men having more hands-on experience.

The women engineers described themselves in terms related to tasks, and found it difficult to use subjective descriptions. Task performance is measurable and tangible results cannot be challenged, while subjective descriptions are a matter of perception and can be judgmental. Their tendency to shy away from subjective description was evident, even when speaking of task performance. They spoke of working hard to complete a task and getting the job done. They did not put a value judgment or label on their performance with adjectives such as doing a good job or finding exceptional solutions.

Many of them were taken aback at these questions and found it difficult to respond. "I don't know. That's a good question. I've never thought about that..." (Maria). "That's really hard, who am I..." (Joy). Engineering is a profession that is based on rational and logical application of the laws of physics, and as engineers, these women took pride in being an engineering professional. The questions about their personal characteristics were unexpected, and they didn't have ready words to describe themselves.

In describing their best quality, the engineers had a task focus and responded that they didn't give up, persevered, and got things done. They responded that they were a hard working, determined, persevering, average group of women. Their credentials and successes didn't seem to color their self-perception. For instance, Mary had engineering BS/MS degrees and had made it to the final cut of 100 in the astronaut program, but didn't see herself as anything special:

I don't know. Gosh, who am I? Pretty average. I know if you look at statistics and stuff there are very few women who have engineering degrees, very few who have Master's, but you know I never really... I just think of myself as pretty average. Just the general population.... Yeah, average. I don't think of myself any different than anyone else. But I think sometimes they think differently... long pause (Mary)

The individual difference research indicates that women attribute success to unstable factors such as luck, while men attribute their success to natural ability or skill. The comments by the women engineers reflect this concept because they never attribute their best quality to a natural ability or skill, but believe that they can do enough, work harder, or stick with it to be successful. They do not see themselves as intelligent, smart people who excel at problem solving.

My best quality, in general, is that I will get the job done. I will do it. Not taking things personally, not having to have it my way, not having a close personal thing built on whether the design is my way or not. Knowing things aren't going to last like they are. It was perseverance. I think that a lot of the people around me doing the same type of work are a lot more knowledgeable... But, I also have a way of going about my work. I'm not very organized, but yet I can keep track of a lot of things. I can think about a lot of things at the same time. I think that's a benefit too. (Joy)

Probably stubbornness. It's just that when I get it stuck in my head that I want to do something, I'll keep trying and trying until I do it and dedication. Getting to the end. Hard work versus 
being very smart. Hard work more, anybody can be book smart, I've seen a lot of people that are very intelligent, more intelligent than me and they don't do anything practical. Even though I may be lacking in experience, I work very hard to make up for that very quickly. I work very hard to get things done and accomplished. I'm very driven to do something; to do a job, do it well, do it quickly. (Dana)

When asked about how they compared to their men peers, the women engineers responded that their peers were better technically, but they, the women, stuck with the task and got things done. They felt that they worked harder, but were not as capable in natural technical ability.

I think I don't give up very easy and if something doesn't work, some people say, “Oh, we can't do it that way." I'll stay late and I make it work. I'm gonna figure out how to get it to work and figure out why it's not working. I'll persevere when other people may not. I think it's my perseverance because I don't think my technical background is that strong. I think there's a lot of more technically smart people here, who have looked into the same stuff, but maybe just dropped it because they didn't feel it was gonna work. I think the technical background is there, but I think it's more perseverance. (Meredith)

I think my ability to get things done even when there's not very good data. But other tasks I've been given, I'll get jobs done. I'm a worker. I think a lot of people around here kind of float through. I think I'm a much more down to earth person than some people. I'd say I'm somewhere in the middle smarts wise. I know there's guys over there who blow me away with their smarts. But, book wise, a lot of them got the hands-on experience wise too. That's something I don't have but I wish I had. I got to be the go-fer a lot helping the guys when they were working on cars and stuff, but I wish I would have joined SAE when I was in college and did more hands-on type of stuff. I think they pull a lot of experience from helping dad in the garage or something, growing up and learning more common sense things, rather than just the book smarts. (Judith)

I think a lot of the people around me doing the same type of work are a lot more knowledgeable. They have worked on their cars, and they have a certain kind of mechanical knowledge that I don't. I think sometimes that hurts me not to be more that way. (Joy)

\section{Changing Perceptions}

If self-talk controls how a person performs, the self-perception of women engineers reflects performers who do not have confidence in their problem solving ability and natural skill. Their self-perception is not one of confidence and creativity. Their self image is distorted and contributes to the mismatch in perception of their fit into the workplace, or incomplete occupational socialization. The women's view reflects more about how they have been socialized to see all women than who they really are. Their thinking can be categorized into the four types of irrational and distorted thinking that often plague women engineers as:

1) Perfection reflects competence - I can work hard enough to accomplish anything. Assures eventual failure due to circumstances out of their control.

2) Worth depends on achievements - My peers may be smarter, but I get it done. Neglects creativity and natural problem solving ability. 
3) Entitlement to fair treatment and ideal conditions - I am not treated like everybody else. Things are different for me. Life is never fair to anyone. A false expectation fostered by social agendas.

4) Generalization from a single incident - youth experience with cars or mechanical devices means better engineering skills. Assumes opportunities are presented to those who are deserving.

These irrational and distracting beliefs can be countered during an engineering education. First, remember that the stage is set for a predisposition of negative perception because engineering is a male oriented discipline and engineering work and problem descriptions are in a socially perceived male context of mechanical systems, devices, language, and models. Women respond best to clear and objective feedback on performance, and although the engineering profession may evaluate performance subjectively, in an engineering education, test scores, class ranking and other objective evaluations can be used to point out ability and skill.

Coaching women engineers to change their view of reality is a five step process that involves replacing generalities with specific events and disputing the irrational arguments ${ }^{13}$. The steps to this process are:

1. Have her identify the specific event that prompted the statement.

2. Evaluate the event. What does the event mean? Is she a failure, will she never get another opportunity?

3. Identify the resulting feelings. As a result, I am angry, depressed, frustrated...

4. Challenging arguments. Why was it unfair? Why shouldn't it be allowed to happen?

5. The answers to the challenging arguments. Yes, it was unfair, but I can... I would like for things to be different, but I'm not necessarily supposed to get my way.

For example, in the category of perfection reflects competence, a student might have the perception that they can work or study hard enough to make an $A$ in a course, when in actuality, working hard can be replaced by working smarter with the help of a tutor, the professor, or a study group. Simply working hard is no replacement for understanding the material, and eventual failure is assured if the only success is measured by making an "A" through hard work. Furthermore, the expectation of making an $A$ may be unrealistic. A healthier approach is to get a strategy for success and then to do your best. Countering this thought process might go like this:

Statement: I just need to study more and work harder to make an $A$.

1. Identify the event. Just exactly what are you trying to accomplish? What has happened to make you believe that working harder is the answer?

2. Evaluate the event. What happens if you don't make an A?

3. Identify the feelings. How do you feel about where you are now?

4. Challenge the beliefs. How can you study harder? How will more work make a difference? How will your plan help you have different results than the past?

5. Answers to the beliefs. What is a workable plan? What can you do?

The goal of this process is to make the person specifically state their belief, engage them in a realistic evaluation of the belief, and to help them replace their irrational thoughts and plans with a realistic plan of action or belief. As a coach, keep asking them questions that require them to 
evaluate the situation realistically by countering socialized beliefs. Always remember to ask questions instead of giving advice or explanations. Have the person explain the situation to themselves with the coach in a role as the devil's advocate.

In the case of generalization from a single event such as having hands-on experience, the process might develop as follows:

Statement: I probably won't be good at that because I've never worked on things before.

1. Identify the event. Now exactly what have you not done before? Explain exactly why you won't be able to solve this problem?

2. Evaluate the event. What happens if you don't get it right the first time? Why is it that you've never had this opportunity?

3. Identify the feelings. How do you feel about trying something new? How do you feel about this type of work? Why?

4. Challenge the beliefs. Just because you've never tried, how does that imply you can't?

5. Answers to the beliefs. What is a plan for you to learn about this? What are the possible results to your trying it? What can you do to better prepare yourself to learn about this?

\section{Conclusions}

Socialization is the worst enemy of women engineers. They don't become dissatisfied in their careers because of a lack of technical ability, but because of social interactions and interpretations of workplace dynamics. The preconceived ideas and perceptions that women have about what they can accomplish and who they are predispose them to unrealistic thoughts and self-perception. Changing these beliefs first requires understanding how women typically perceive themselves in achievement and workplace environments, and then coaching them to replace these irrational thoughts with realistic ones.

Women and men view themselves and value their achievements differently. Thus, a different strategy must be used with each gender to provide more realism to their self-perception. Women attribute success to luck, while men attribute success to natural ability or skill. In coaching women, they must be taught to acknowledge their ability and skill. They must be taught to have confidence in their ability to solve problems. Their classroom performance can be used as evidence that they are unique in their problem solving ability - not simply average.

Women engineers believe that they are only average in ability, and that their men peers are more capable. They attribute this ability to the perceptions of gender-types roles and specifically that men have much more hands-on ability and experience. Their thoughts unrealistically take this social perception as an indicator of their natural ability when the truth of the matter is that most women have not had the opportunity to perform hands-on experience.

Irrational thoughts for women engineers are categorized into four types: perfection reflects competence, worth depends on achievements, entitlement to fair and ideal conditions, and generalization from a single incident. Each of these categories has challenging arguments that can aid in replacing distorted thoughts with realistic thoughts. 
Coaching women to have a more realistic view of themselves can be accomplished with a five step process that converts generalizations about circumstances into specific events, challenges the erroneous perceptions, and insists on a change plan based on more rational premises. Using this process requires asking the person to explain what they base their premise on, what the reasons are for this situation, and what they plan to do next.

More women are entering the technical professions that ever before. They are sorely needed to provide skills and expertise. Their technical skills are not in question, and more and more, they are a welcome resource. However, to stay in a full career, women need additional social preparation that doesn't naturally come with our social upbringing. Women don't need additional training, they need to realistically understand who they are, the workplace and its dynamics, and how they fit in. This accurate perception can be fostered during an engineering education by carefully listening to the student's description of themselves and their plan, and careful challenging of false impressions. Learning social skills isn't a matter of practice or by rote - it requires coaching, listening, and feedback.

Performance at a high level requires self-confidence and an accurate self-perception. We can only do what we believe we can accomplish. Women engineering students need for their unique problem solving ability to be pointed out and reinforced. They need to understand that they can be creative, that they may not always get a solution, and that they can accomplish their careers through their ability, not be simply outlasting everyone else.

\section{References}

${ }^{1}$ Holloway, Marguerite (1993, November). A lab of her own. Scientific American, 94-103.

${ }^{2}$ Morris, Betsy (1995). Executive women confront mid-life crisis. FORTUNE, 132(6), 60-86.

${ }^{3}$ Acosta, R. Vivian \& Carpenter, Linda Jean (1996). Women in intercollegiate sport: A longitudinal study - 17 year update, 1977-1996. Women's Sports Foundation, East Meadow, NY.

${ }^{4}$ Hart, Barbara A., Hasbrook, Cynthia A., \& Mathes, Sharon A. (1986). An examination of the reduction in the number of female interscholastic coaches. Research Quarterly for Exercise and Sport, 57(1), 68-77.

${ }^{5}$ Catalyst (1992). Women in engineering : An untapped resource. New York. Catalyst, 21,23,18.

${ }^{6}$ Deaux, K. (1984). From individual differences to social categories: A decade's research on gender. American Psychologist, 39, 105-116.

${ }^{7}$ Yoder, Janice D. (1991). Rethinking tokenism: Looking beyond numbers. Gender \& Society, (2), $178-192$.

${ }^{8}$ Lenney, E. (1977). Women's self-confidence in achievement settings. Psychological Bulletin, 84, 1-13.

${ }^{9}$ Bunker, Linda, Williams, Jean M., \& Zinsser, Nate (1993). Cognitive techniques for improving performance and building confidence. In Jean M. Williams (Ed.), Applied sport psychology: Personal growth to peak performance, $2^{\text {nd }}$ Edition, (pp 225-242).

${ }^{10}$ Bell, K. F. (1983). Championship thinking: The athlete's guide to winning performance in all sports. Englewood Cliffs, NJ. Prentice-Hall. 
${ }^{11}$ Ellis, A. \& Harper, R. (1975). A new guide to rational living. Englewood Cliffs, NJ: Prentice Hall.

${ }^{12}$ Seat, Janie Elaine (1996). Women Engineers: Expectations and perceptions. Doctoral Dissertation. University of Tennessee, Knoxville, Tennessee.

${ }^{13}$ Thompson, Charles L. \& Rudolph, Linda B. (1988). Counseling Children. $2^{\text {nd }}$ Ed. Brooks/Cole Publishing Co., Pacific Grove, CA.

\section{Biography}

\section{ELAINE SEAT}

Elaine Seat received B.S. and M.S. degrees in Mechanical Engineering and is a licensed Professional Engineer. Her $\mathrm{Ph} . \mathrm{D}$. is in Sport Psychology from the University of Tennessee, Knoxville. She is a researcher at Lockheed Martin Energy Systems in visualization and training through simulation, and teaches human performance topics for technical majors as an adjunct professor in Counseling Psychology at the University of Tennessee, Knoxville.

Correspondence regarding this work can be addressed to Elaine Seat, 801 Forest Heights Road, Knoxville, Tennessee, 37919, or she may be reached by e-mail at jeseat@ usit.net. 